\title{
Wave Forcing of the Tropical Upwelling in the Lower Stratosphere under Increasing Concentrations of Greenhouse Gases
}

\author{
Natalia CALvo \\ National Center for Atmospheric Research,* Boulder, Colorado, and Departamento de Fisica de la Tierra II, \\ Universidad Complutense de Madrid, Madrid, Spain \\ ROLANDO R. GARCIA \\ National Center for Atmospheric Research,* Boulder, Colorado
}

(Manuscript received 27 January 2009, in final form 4 May 2009)

\begin{abstract}
Two simulations from the Whole Atmosphere Community Climate Model, covering the periods 1950-2003 and 1980-2050, are used to investigate the nature of the waves that force the increase of the tropical upwelling in the lower stratosphere as the concentration of greenhouse gases increases. Decomposition of the wave field resolved by the model into stationary and transient wavenumber spectra allows attribution of trends in the Eliassen-Palm (EP) flux and its divergence to specific wave components. This analysis reveals that enhanced dissipation of stationary planetary waves is the main driver of trends in the tropical upwelling in the lower stratosphere. The contribution of transient waves is smaller and is responsible mainly for trends in wave forcing in the subtropics and middle latitudes, which, however, provide only minor contributions to the mean tropical upwelling. Examination of individual wave structures shows that the stationary waves are tropical Rossby waves trapped in the upper troposphere and lower stratosphere, whereas the transient components are synoptic waves present in the subtropics and middle latitudes. The authors also present evidence that trends in resolved wave forcing in the lower stratosphere are due to both changes in wave transmissivity and changes in wave excitation, with the first mechanism dominating the behavior of the simulation during the last half of the twentieth century, while the second is clearly more important in the simulation during the first half of the twenty-first century.
\end{abstract}

\section{Introduction}

Several recent studies have pointed out the effects of climate change induced by greenhouse gases (GHGs) on the stratospheric mean meridional, or Brewer-Dobson (BD), circulation (e.g., Butchart and Scaife 2001; Rind et al. 2001; Shindell et al. 2001; Sigmond et al. 2004; Butchart et al. 2006; Eichelberger and Hartmann 2005; Olsen et al. 2007; Oman et al. 2009). In particular, Butchart et al. compared simulations from several general circulation models and found that they predicted an

\footnotetext{
* The National Center for Atmospheric Research is sponsored by the National Science Foundation.
}

Corresponding author address: Natalia Calvo, National Center for Atmospheric Research, P.O. Box 3000, Boulder, CO 803073000.

E-mail: calvo@ucar.edu increase in the mass flux at the tropical tropopause in response to growing greenhouse gas concentrations of about $2 \%$ per decade. Recently, Garcia and Randel (2008, hereafter GR08) used the Whole Atmosphere Community Climate Model (WACCM) to show that, in this model, the tropical upwelling increases and age of air (Hall and Plumb 1994) decreases as a result of enhanced propagation of wave activity from the troposphere, which dissipates in the subtropical lower stratosphere. GR08 suggested that these changes are linked to trends in the zonal-mean zonal wind structure of the upper troposphere and lower stratosphere, which in turn follow from changes in the zonal-mean temperature distribution caused by the increase in GHGs. Further analysis of the Eliassen-Palm (EP) flux and its divergence revealed that trends in wave driving in the lower stratosphere, below about $20 \mathrm{~km}$, were due mainly to forcing by waves resolved explicitly in the model, the influence of parameterized gravity waves being small in the lower stratosphere. 
Most of the studies mentioned above, however, do not agree on the nature of the waves responsible for the acceleration of the BD circulation in the tropical lower stratosphere. It is unclear, for example, whether the waves in question are planetary or synoptic waves, stationary or transient, and whether they originate in middle latitudes or in the tropics. There is also no general agreement on what mechanisms might be responsible for the increases in wave driving that accelerate the stratospheric circulation. Butchart and Scaife (2001) used a troposphere-stratosphere version of the U.K. Meteorological Office's Unified Model to study the acceleration of the $\mathrm{BD}$ circulation following from a doubling of the concentration of $\mathrm{CO}_{2}$. They found that the acceleration was related to an increased flux of wave activity from the troposphere. The increase of wave activity flux coincided with regions of positive (westerly) trend in the zonal-mean zonal wind, similar to the finding of GR08. Along the same lines, Olsen et al. (2007) studied the atmospheric response to changes in sea surface temperatures (SSTs) that result from increasing atmospheric GHGs with the Goddard Earth Observing System (GEOS) general circulation model (GCM). They showed that warmer SSTs in the tropical upper troposphere change the propagation characteristics of waves emanating from the troposphere. However, Olsen et al. also found that the changes enhanced poleward refraction, which in turn resulted in greater wave dissipation and wave driving in the polar stratosphere rather than in the subtropics as reported by GR08. The results of Sigmond et al. (2004) are also consistent with the idea that changes in wave driving arise from changes in the propagation of the waves in question, since they could not find an increase in tropospheric wave activity in their analysis of a doubled- $\mathrm{CO}_{2}$ simulation.

Other studies have emphasized changes in wave excitation as the mechanism for increased driving of the stratospheric circulation. Eichelberger and Hartmann (2005) used a simple atmospheric GCM that included a tropical heat source meant to simulate the effect of a doubling of $\mathrm{CO}_{2}$. They documented an increase in the eddy heat flux associated with both planetary and synoptic waves in midtroposphere and concluded that the increase in synoptic-wave heat flux was due to enhanced baroclinicity in the troposphere, whereas the increase in planetary-wave heat flux was the result of energy transfer from the synoptic waves. Nonetheless, they found that the largest changes in stratospheric wave driving took place in the subtropics and were associated with planetary waves of zonal wavenumber 2 . Deckert and Dameris (2008) used simulations made with the E39/C chemistry-climate model to show that higher tropical SSTs in the summer hemisphere strengthen convective heating, and as a result the excitation and dissipation of quasi-stationary waves intensifies in the tropical lower stratosphere. Oman et al. (2009) also highlight the influence of SSTs in GEOS chemistry-climate model simulations in forcing the increase in upwelling observed in the tropics, in particular in future climates when the SSTs are warmest. Fomichev et al. (2007) analyzed a double- $\mathrm{CO}_{2}$ experiment carried out with the Canadian Middle Atmosphere Model (CMAM) and did not observe noticeable changes in upward propagating planetary wave activity in the extratropical stratosphere but emphasized instead enhanced forcing at subtropical latitudes.

Very recently, McLandress and Shepherd (2009) have used an updated version of CMAM to investigate the types of wave involved in the acceleration of the $\mathrm{BD}$ circulation. They concluded that the increase in the annual-mean tropical upward mass flux at $70 \mathrm{hPa}$ is due mainly to the increase in wave drag at subtropical latitudes caused by resolved planetary waves. Orographic gravity waves also contribute to the upwelling trend, and this contribution increases with increasing altitude above the tropopause. Whereas near $100 \mathrm{hPa}$ the contribution of gravity waves to the tropical upwelling trend is insignificant, at $70 \mathrm{hPa}(\sim 18.6 \mathrm{~km})$ it increases to account for $40 \%$ of the trend. This is about the same as reported by GR08 (their Fig. 4), although above $70 \mathrm{hPa}$ the relative contribution of gravity waves becomes larger in the CMAM results than in the results reported by GR08, possibly due to the different methods of averaging the tropical upwelling used by GR08 and McLandress and Shepherd. In any case, McLandress and Shepherd conclude that the mechanisms that lead to the increase in planetary wave driving in the lower stratosphere are not understood.

The works cited above are consistent in the conclusion that upwelling trends in the lower stratosphere are driven mainly by trends in planetary wave driving, but this result is not universal. Li et al. (2008), using the Atmospheric Model with Transport and Chemistry (AMTRAC) chemistry-climate model from the Geophysical Fluid Dynamics Laboratory, have shown that changes in orographic gravity wave drag are more important than changes in planetary EP flux divergence in producing trends in tropical upwelling at altitudes as low as $77 \mathrm{hPa}(\sim 18 \mathrm{~km})$, although this occurs only in $\mathrm{NH}$ winter.

It is clear from the foregoing discussion that closer examination of the causes of tropical upwelling trends is needed in order to understand how climate change brings about such trends. In the present paper we attempt to do this by investigating the temporal and spatial scales and structure of the waves involved in the increase of tropical upwelling calculated in WACCM in 
the lower stratosphere, below about $20 \mathrm{~km}(50-60 \mathrm{hPa})$. This is the region where the largest trends in age of air are found in WACCM, and where they are due to changes in wave forcing by explicitly resolved waves. Section 2 of the paper introduces the model and simulations analyzed, and the methodology used in the analyses; section 3 presents the results, including attribution of trends in EP flux and its divergence to specific waves, and an examination of possible mechanisms for such trends; and section 4 discusses and summarizes our conclusions.

\section{Model, simulations, and methodology}

\section{a. Model and simulations}

The version of WACCM used here (version 3 ) is a fully coupled chemistry-climate model based on version 3 of the Community Atmospheric Model (CAM3) developed at the National Center for Atmospheric Research (NCAR). Detailed information about the model can be found in Garcia et al. (2007). The domain spans the range of altitudes from the surface to about $140 \mathrm{~km}$. The vertical resolution varies from about $1.25 \mathrm{~km}$ in the troposphere and lower stratosphere to $1.75 \mathrm{~km}$ in the upper stratosphere, and about $3.5 \mathrm{~km}$ in the upper mesosphere and thermosphere. The simulations discussed in this paper were carried out at horizontal resolution of $4^{\circ} \times 5^{\circ}$ (latitude $\times$ longitude).

As in GR08, we have used two ensembles of simulations, designated REF1 and REF2, with three realizations each. REF1 is a "retrospective" simulation of the second half of the twentieth century (1950-2003), run with observed SSTs and observed concentrations of GHGs $\left(\mathrm{CO}_{2}, \mathrm{~N}_{2} \mathrm{O}\right.$, and $\left.\mathrm{CH}_{4}\right)$ and halogen species. REF2 is a prognostic simulation, spanning the period 1980 2050, wherein GHGs are specified according to scenario A1B of the Intergovernmental Panel for Climate Change (IPCC; Houghton et al. 2001) and halogen concentrations follow Table 4B-2 of the World Meteorological Organization's Ozone Assessment Report (WMO 2003). The SSTs are specified from a run made with NCAR's CAM3, upon which WACCM is based, coupled with a full ocean model and with GHGs also specified according to IPCC scenario A1B.

\section{b. Methodology}

To characterize the waves that contribute to the increased wave dissipation discussed above, the EP flux and its divergence have been computed for stationary and transient fields and for each wavenumber. To do so, daily eddy zonal and meridional wind, potential temperature, and vertical velocity fields were separated into their stationary and transient parts, with the stationary component defined as the time mean for each month, and the transient component calculated as the difference between the daily values and the monthly mean. A Fourier decomposition of the stationary and transient fields was then carried out, and the EP flux was computed as a function of zonal wavenumber for both the stationary and transient components:

$$
\mathbf{F}=\left(\sum_{k} F_{y k}, \sum_{k} F_{z k}\right),
$$

where

$$
\begin{aligned}
& F_{y k}=\rho_{0} a \cos \phi\left[\bar{u}_{z} \frac{0.5 \operatorname{Re}\left(v_{k} \theta_{k}^{*}\right)}{\bar{\theta}_{z}}-0.5 \operatorname{Re}\left(u_{k} v_{k}^{*}\right)\right], \\
& F_{z k}=\rho_{0} a \cos \phi\left\{\left[f-\frac{1}{a \cos \phi} \frac{\partial}{\partial \phi}(\bar{u} \cos \phi)\right] \frac{v_{k} \theta_{k}^{*}}{\bar{\theta}_{z}}-u_{k} w_{k}^{*}\right\},
\end{aligned}
$$

where $f$ is the Coriolis parameter; $\bar{u}, \bar{\theta}$ are the zonalmean zonal wind and potential temperature, respectively; $u_{k}, v_{k}, \theta_{k}$ represent the $k$ th wavenumber components of the velocity and potential temperature fields (asterisks denote their complex conjugates); $a$ is the earth's radius; $\phi$ is the latitude; and $z$ is $\log$-pressure altitude. Monthly averaged values are used for the zonal-mean quantities $\bar{u}$ and $\bar{\theta}$ in Eq. (2).

Decomposition of the EP flux according to Eqs. (1) and (2) for stationary and transient components requires high-frequency output (at least daily) for all the relevant fields. It was noted by GR08 that, in the REF1 and REF2 simulations, the zonally averaged fluxes $\overline{u^{\prime} v^{\prime}}, \overline{v^{\prime} \theta^{\prime}}, \overline{w^{\prime} \theta^{\prime}}$ were output on a daily basis, but that this did not allow decomposition by wavenumber or by transient versus stationary motions. Here we have circumvented this problem as follows: daily output for $u^{\prime}, v^{\prime}$, and $\theta^{\prime}$ is available and it turns out that $w^{\prime}$ can be deduced accurately enough from $u^{\prime}$ and $v^{\prime}$ via the continuity equation. This allows us to compute all the terms necessary to evaluate Eqs. (1) and (2). 


\section{Results}

\section{a. Attribution of trends in wave forcing}

As noted in the introduction, much of the increase in the tropical upwelling calculated by WACCM in the lower stratosphere, below about $20 \mathrm{~km}$, is due to the enhanced flux and dissipation of resolved wave activity in the subtropics. Figures 1 and 2 show the ensemblemean monthly-mean trend of the EP flux vector superimposed on the ensemble-mean monthly-mean trend of the EP flux divergence for stationary and transient waves in the REF1 and REF2 simulations, respectively, between 15 and $25 \mathrm{~km}$. These are linear trends computed from deseasonalized, monthly-mean fields. We have verified that the sum of the trends due to the combination of stationary and transient waves of all wavenumbers (upper row of Figs. 1 and 2) is nearly identical to the total trend due to resolved waves shown in GR08 (their Fig. 3). The results shown in Figs. 1 and 2 indicate that, in both simulations, stationary waves explain most of the trend in the EP flux divergence in the tropics and subtropics while the transients are responsible for the trend calculated in middle latitudes. The EP flux trend vectors due to stationary waves originate mainly in the lower tropical stratosphere and turn poleward, whereas the trend vectors for the transient EP flux are large in middle latitudes and turn equatorward. The REF1 simulation shows larger trends in the stationary component of EP flux and EP flux divergence than REF2; on the other hand, larger trends in the transient EP flux and its divergence are observed in REF2 in the NH subtropics and middle latitudes. The wavenumber decomposition (lower two rows in Figs. 1 and 2) reveals that planetary waves (wavenumbers 1-3) account for most of the trends due to the stationary waves. For the transients, both planetary and synoptic waves (wavenumbers 4-6) produce comparable trends. Wavenumbers beyond $k=6$ contributed insignificantly to the trends in EP flux divergence.

As shown by GR08, changes in subtropical wave driving explain the upwelling trend calculated in the lower stratosphere by WACCM. The contribution of stationary and transient waves of different wavenumber to the tropical upwelling can be computed by applying the downward control principle (Haynes et al. 1991). GR08 used the following expression for the tropical average, over latitudes $\pm \phi_{0}$, of the transformed Eulerian mean (TEM) vertical velocity:

$$
\left\langle\bar{w}^{*}\right\rangle(z)=\frac{\frac{1}{\rho(z)}\left|\int_{z}^{\infty} \frac{\rho a \cos ^{2} \phi\left[(\rho a \cos \phi)^{-1} \nabla \cdot \mathbf{F}\left(\phi, z^{\prime}\right)\right]}{\bar{m}_{\phi}} d z^{\prime}\right|_{-\phi_{0}}^{+\phi_{0}}}{|\sin \phi|_{-\phi_{0}}^{+\phi_{0}}},
$$

which states that $\left\langle\bar{w}^{*}\right\rangle$ depends only on the value of the vertical integral in Eq. (3) evaluated at the edges of the tropical region, $\pm \phi_{0}$. In WACCM the bulk of the tropical upwelling at altitudes between 15 and $35 \mathrm{~km}$ occurs within $30^{\circ}$ of the equator in the annual mean, as shown in Fig. 3 for REF2. (Almost identical results are obtained for the REF1 simulation; not shown.) In the lowermost stratosphere, however, the upwelling branch of the circulation is even more tightly confined around the equator. We have used $\phi_{0}=22^{\circ}$ in all the calculations presented below, as this choice captures the bulk of the upwelling at all altitudes.

Figure 4 shows vertical profiles of the ensemble-mean monthly-mean trend in $\left\langle\bar{w}^{*}\right\rangle$ computed using (1)-(3) for the stationary and transient EP flux components in the REF1 and REF2 simulations (solid lines). The individual contributions of planetary and synoptic waves are denoted by the dashed and dot-dashed lines, respectively. It is evident that the trend due to the stationary waves is much larger than the trend due to the transients, and that this trend is dominated by the contribution of the planetary waves, which account for about $80 \%$ of the total stationary trend in both REF1 and REF2. For the transient waves, the planetary scales still explain much of the trend, but the difference between planetary and synoptic waves is considerably reduced compared with the stationary component, especially in the REF2 simulation, where synoptic waves account for over $40 \%$ of the total transient trend. We emphasize that, above about $25 \mathrm{~km}$, the trends in vertical velocity shown in Fig. 3 are not representative of the total trend because, in the middle and upper stratosphere, a large part of that trend is due to changes in forcing due to parameterized gravity waves (cf. GR08, their Fig. 4). However, the focus of the present investigation is on the attribution of upwelling trends in the lower stratosphere, below $20 \mathrm{~km}$, where in WACCM the trends are controlled by changes in the behavior of resolved waves.

An interesting feature of the tropical upwelling trends shown in Fig. 4 is the fact that they are attributable mainly to trends in forcing by stationary planetary waves, even though the EP flux trends due to transient waves shown in Figs. 1 and 2 are by no means negligible. 

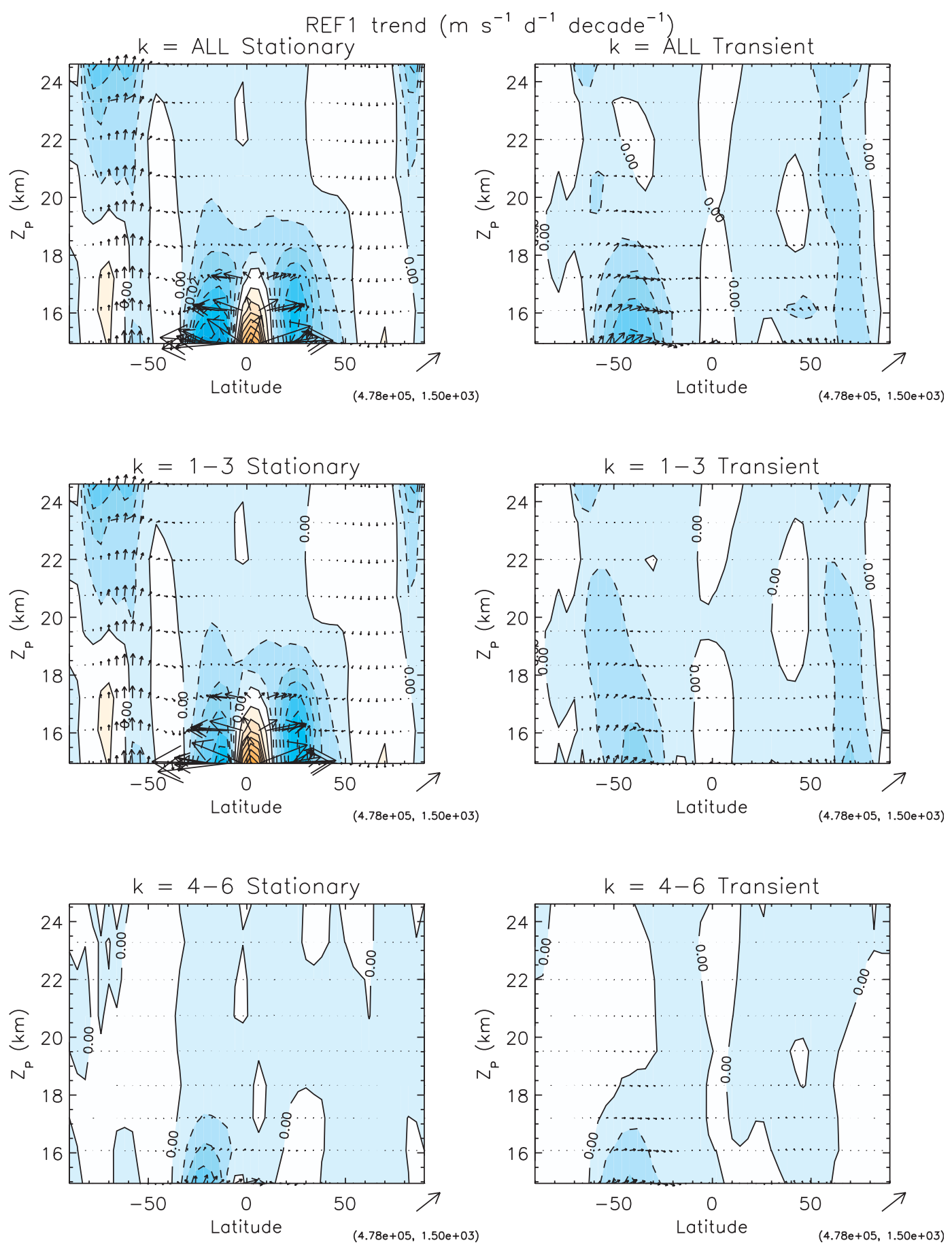

FIG. 1. Ensemble trend of EP flux (arrows, $\mathrm{kg} \mathrm{s}^{-2}$ decade ${ }^{-1}$ ) and EP flux divergence $\left(\mathrm{m} \mathrm{s}^{-1} \mathrm{day}^{-1}\right.$ ) for (left) stationary and (right) transient waves in the REF1 simulation including (top) all wavenumbers; (middle) planetary waves $(k=1-3)$ only; and (bottom) synoptic waves $(k=4-6)$ only. EP flux divergence contour intervals are $0.02 \mathrm{~m} \mathrm{~s}^{-1}$ day $^{-1}$ decade $^{-1}$ for positive values and $0.01 \mathrm{~m} \mathrm{~s}^{-1}$ day $^{-1}$ decade $^{-1}$ for negative values; red shading denotes positive trends and blue shading negative trends. Trends smaller than $\pm 0.01 \mathrm{~m} \mathrm{~s}^{-1} \mathrm{day}^{-1} \mathrm{decade}^{-1}$ are not shaded. All trends are computed from deseasonalized, monthly-mean model output. The scale of the EP flux trends is indicated by the arrow at the bottom right of each panel; the same scale is used in all panels. Vector EP flux is plotted as $\cos \phi\left(a^{-1} F_{y}, F_{z}\right)$, where $\phi$ is latitude and $a$ is the earth's radius, which makes the pattern appear nondivergent in the $(\phi, z)$ plane (Edmon et al. 1980). 

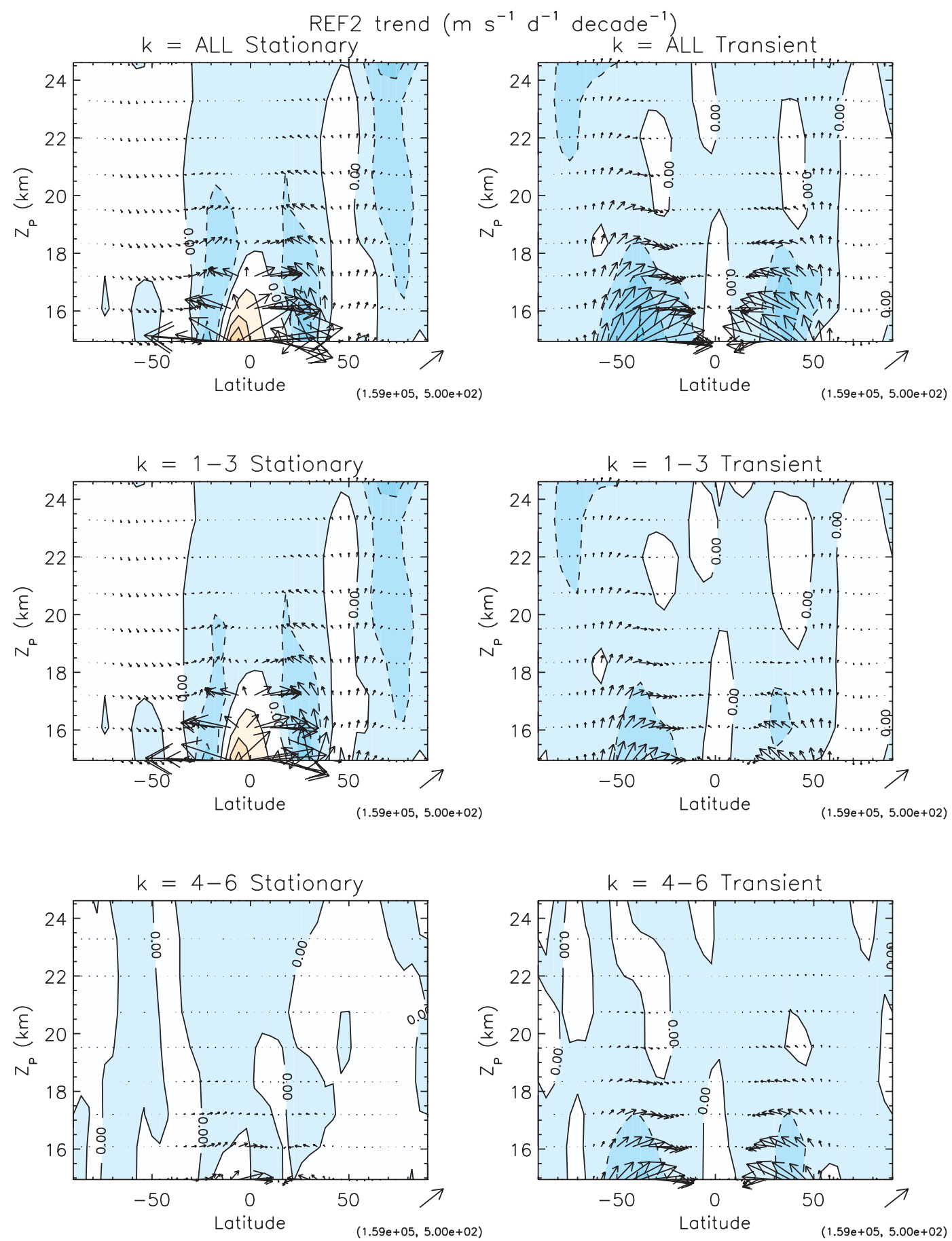

FIG. 2. As in Fig. 1 but for the REF2 simulation. Note that the scale for EP flux divergence is the same as in Fig. 1 but the scale for EP flux differs and is indicated by the arrow at the bottom right of each panel. The same scale in EP flux is used in all panels.

However, the transient waves produce EP flux trends centered at middle latitudes, while much of the EP flux trend due to stationary waves is centered in the subtropics; Eq. (3) predicts that only the latter contributes to the mean tropical upwelling, which we have defined as the average between latitudes $\pm 22^{\circ}$. Thus, although transient waves modify the extension of the BD circulation to middle and high latitudes, their contribution to the upwelling branch in the tropical lower stratosphere is substantially smaller than that of the stationary waves. 


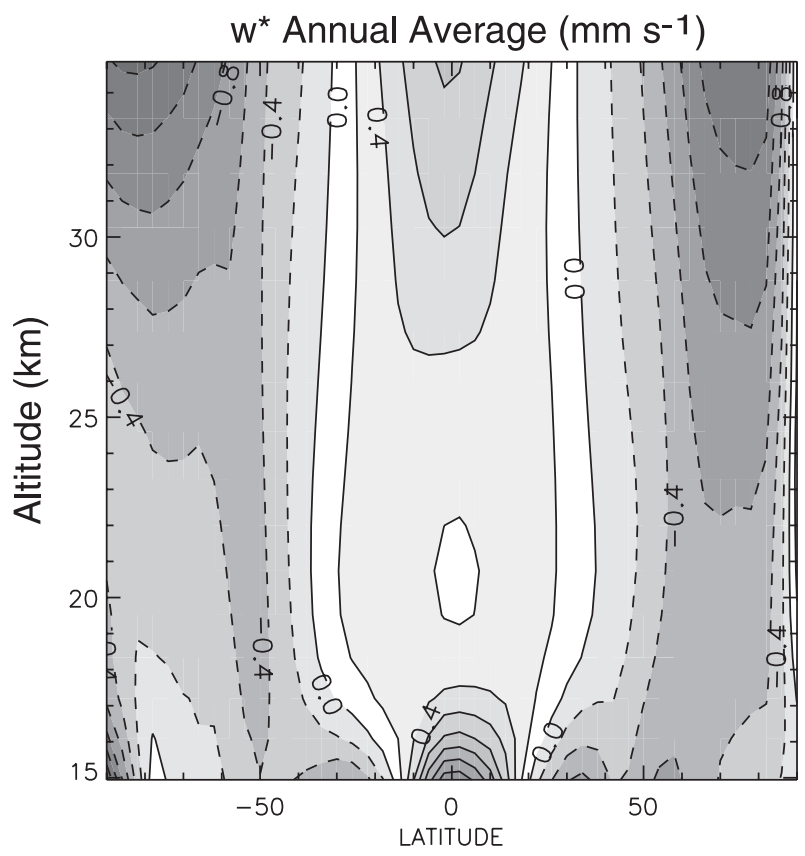

FIG. 3. Annual-mean TEM vertical velocity averaged over the entire REF2 simulation. The contour interval is $0.2 \mathrm{~mm} \mathrm{~s}^{-1}$. Solid (dashed) contours for positive (negative) values.

We examine next the waves responsible for the largest contributions to the increase in tropical upwelling. Figure 5 shows wavenumber-frequency spectra of WACCM geopotential for simulation REF1 in the upper troposphere $(12 \mathrm{~km})$ at two different latitudes, one in the tropics $\left(22^{\circ} \mathrm{N}\right)$ and one in midlatitudes $\left(46^{\circ} \mathrm{N}\right)$. The spectra are derived from daily data over one entire year of simulation (1990). Spectra for other years, and for simulation REF2 (not shown), are similar. In the tropics the spectrum is dominated by stationary waves, with largest amplitudes in the planetary scale range, $k=1-3$ and little power elsewhere. In midlatitudes power is also large for quasi-stationary planetary waves, but in addition there is significant transient power at eastward frequencies, which is a manifestation of traveling, baroclinically unstable synoptic disturbances (see, e.g., Holton 1992). In particular, among the synoptic scales $k=4-6$ there is substantial power at frequencies in the range $0.1-0.2 \mathrm{cpd}$ (periods of 5-10 days, i.e., the range of time scales usually associated with baroclinic waves). Thus, the WACCM wave spectrum in the upper troposphere is dominated by stationary planetary waves in the tropics, whereas in midlatitudes both stationary planetary waves and eastwardtraveling synoptic-scale waves are prominent.

To visualize the structure of these waves, daily data were used to compute the amplitudes of the stationary and transient components of different wavenumbers, as explained in section 2. Wavenumbers 1 and 4 have the largest amplitudes among planetary and synoptic scales, respectively, and produce the largest contributions to the EP flux divergence in their respective ranges of wavenumber, so they are used in what follows to characterize the role of stationary and transient waves in WACCM. It is important to note, however, that other wavenumbers in the range $k=1-6$ also contribute significantly to the total stationary and transient wave fields, as seen in the spectra of Fig. 5. Time-mean geopotential height structures for stationary $k=1$ and transient $k=4$ waves in the REF1 simulation (19502003) are shown in Fig. 6. (The corresponding wave structures in REF2 are very similar and are not shown.) The stationary $k=1$ component has the structure of an equatorially trapped Rossby wave (e.g., Gill 1980) in the tropical upper troposphere-lower stratosphere while, at high latitudes, the structure is that of a quasigeostrophic Rossby wave (e.g., Matsuno 1970) that propagates well into the stratosphere. Because the extratropical Rossby waves dissipate at higher latitudes and altitudes they do not contribute strongly to tropical upwelling in the lower stratosphere (although they can and do contribute to trends at higher altitudes; cf. GR08, their Fig. 3). The transient $k=4$ component has the characteristic structure of a synoptic disturbance (e.g., Holton 1992), with largest amplitude in middle latitudes and confined to the troposphere and lower stratosphere.

\section{b. Origin of the trends in wave forcing}

Identification of the waves involved in the acceleration of the BD circulation can help guide the search for the mechanisms responsible for trends in wave forcing. As noted in the introduction, GR08 speculated that, in the lower stratosphere, such trends might be due to enhancements in the propagation of wave activity into the region, since they could not find any clear evidence of increases in wave excitation in the troposphere. We revisit this issue here by looking in detail at two diagnostic quantities: trends in the wave index of refraction (Matsuno 1970) and changes in the latent heat release associated with tropical convection. The first is an indicator of changes in the transmissivity of waves into the stratosphere, while the second is a measure of changes in wave excitation.

Matsuno (1970) used the steady-state quasigeostrophic vorticity equation to define an index of refraction for waves propagating in the latitude-height plane. For stationary waves, Matsuno's squared index of refraction for waves of zonal wavenumber $k$ is given by

$$
n_{r}^{2}=\frac{\bar{q}_{\phi}}{\cos \phi\left(\omega-i \alpha k^{-1}\right)}-\frac{f^{2} a^{2}}{4 N^{2} H^{2}}-\left(\frac{k}{\cos \phi}\right)^{2}
$$



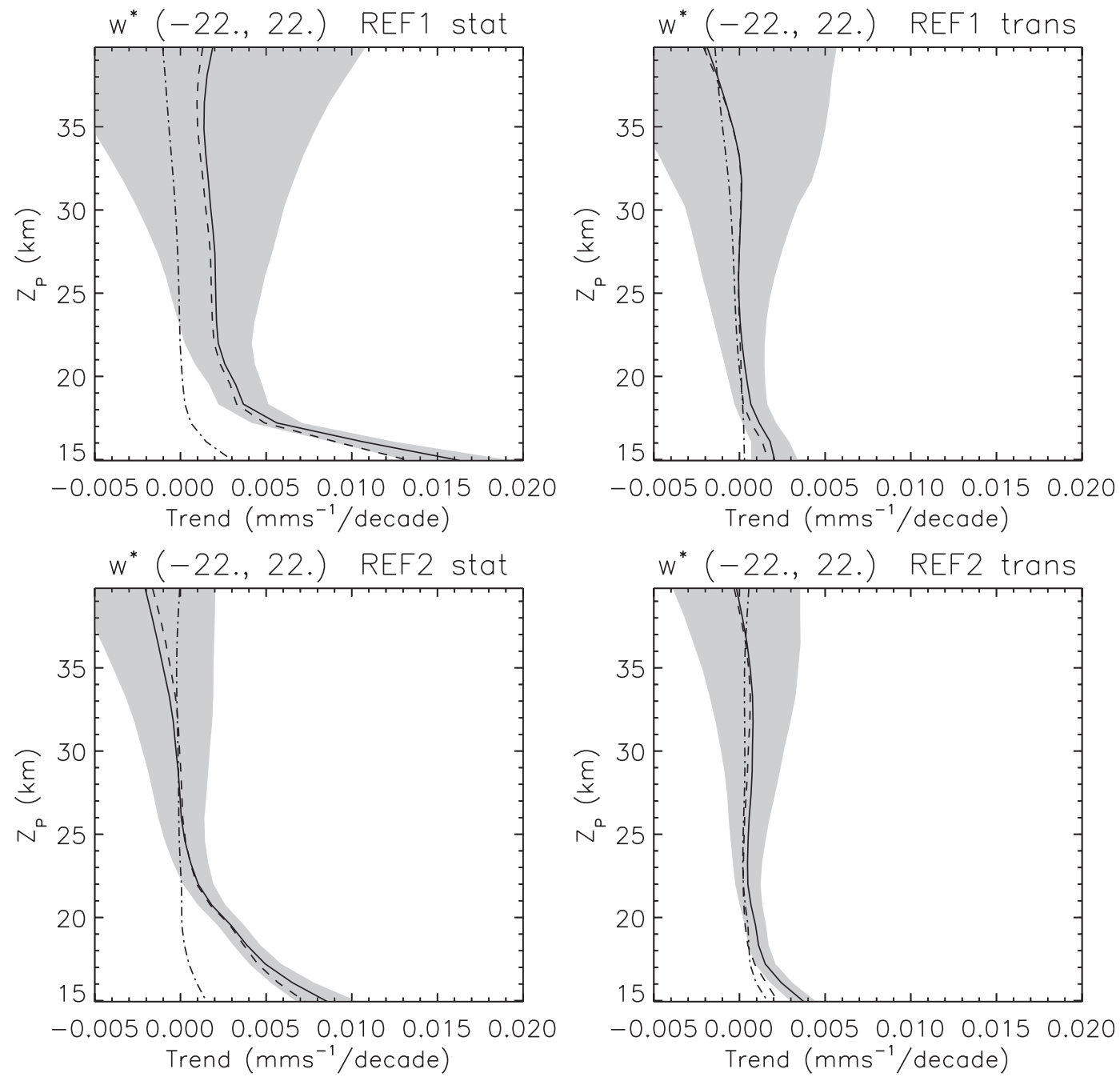

FIG. 4. Ensemble-mean trend of TEM vertical velocity averaged over latitudes $22^{\circ} \mathrm{N}-22^{\circ} \mathrm{S}\left(\mathrm{mm} \mathrm{s}^{-1} \mathrm{decade}^{-1}\right)$ calculated from the downward control principle for (left) stationary and (right) transient waves in the REF1 and REF2 simulations using deseasonalized, monthly-mean model output. The solid lines show the results including both planetary $(k=1-3)$ and synoptic $(k=4-6)$ waves; the dashed lines include only the planetary waves; and the dasheddotted lines only the synoptic waves. The shading denotes two times the standard deviation $(2 \sigma)$ of the trend in vertical velocity computed using the downward control principle including all the waves.

where $\bar{q}_{\phi}$ is the zonal-mean meridional gradient of potential vorticity; $\widehat{\omega}=\bar{u}(a \cos \phi)^{-1}$ is the angular velocity of the zonal-mean flow; $a$ is the earth's radius; $f$ is the Coriolis parameter; $H$ and $N$ are the atmospheric-scale height and buoyancy frequency, respectively; and $\alpha$ is a damping rate, which Matsuno ascribed to equal rates of dissipation of momentum and energy via Rayleigh friction and Newtonian cooling, respectively, but which may be interpreted in a more modern context as the rate of dissipation of eddy vorticity due to wave breaking. In any case, the main purpose of $\alpha$ is to eliminate singularities associated with zero-wind lines, and we have set it to a small value, $\alpha=0.02$ days $^{-1}$, in our evaluation of Eq. (4).
Figure 7 shows the trend in $n_{r}^{2}$ for the REF1 and REF2 simulations in boreal winter [December-February (DJF)], with the trend in vector EP flux due to waves of $k=1$ superimposed thereon. In REF1 (upper panel of Fig. 7), the most striking feature is the increase in $n_{r}^{2}$ in the tropical upper troposphere and lowermost stratosphere, which coincides with the region of largest trends in vector EP flux. In fact, the trend in $n_{r}^{2}$ has the effect of changing the values of $n_{r}^{2}$ from negative to positive below $17 \mathrm{~km}$ in the deep tropics, thus allowing wave propagation in a region where formerly the waves were evanescent. Similar results are obtained for other seasons in the REF1 simulation, suggesting that modification of the zonal-mean zonal winds, and its effect on the 

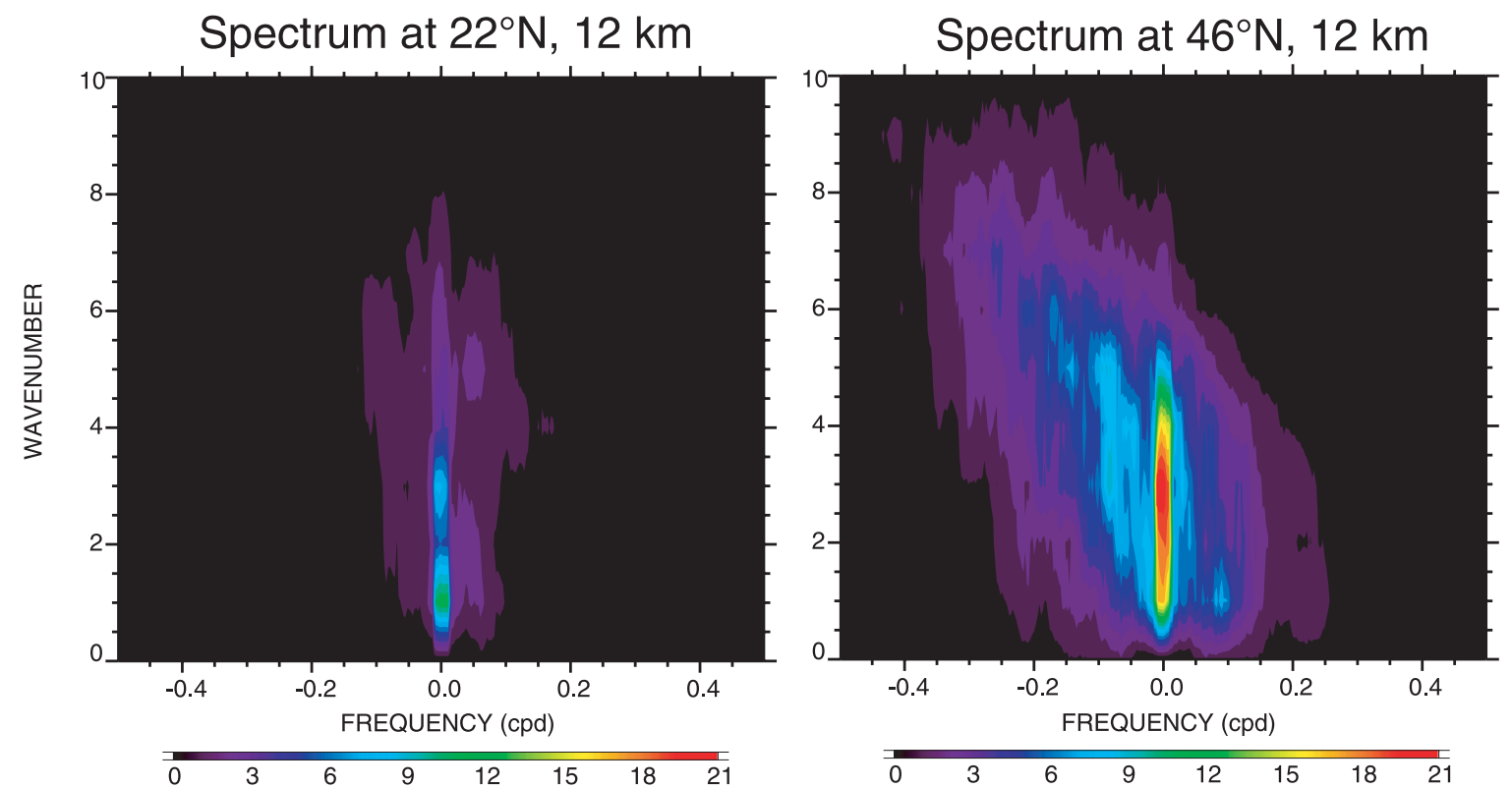

FIG. 5. Geopotential height amplitude spectra (m) derived from daily WACCM output for simulation REF1, year 1990. (left) Tropical upper troposphere. (right) Midlatitude upper troposphere. Negative frequencies represent eastward-propagating waves; positive frequencies represent westward-propagating waves.

propagation characteristics of quasi-stationary waves, may be the dominant factor in producing the trends in vector EP flux obtained in the REF1 simulation. (Recall from Fig. 4 that stationary planetary waves account for essentially the entire trend in tropical upwelling in REF1, and $k=1$ dominates the trend due to planetary-scale waves.)

Although the foregoing analysis seems to confirm the importance of changes in wave propagation, as con- jectured by GR08, a similar calculation using the results of simulation REF2 (lower panel of Fig. 7) does not yield a significant $n_{r}^{2}$ trend in the tropics, which implies that changes in wave propagation are not responsible for the trends in vector EP flux in the lower stratosphere in that simulation. Changes in wave excitation then are presumably involved, but GR08 could not find significant changes in upward EP flux emanating from the lower troposphere. Because the wave activity that
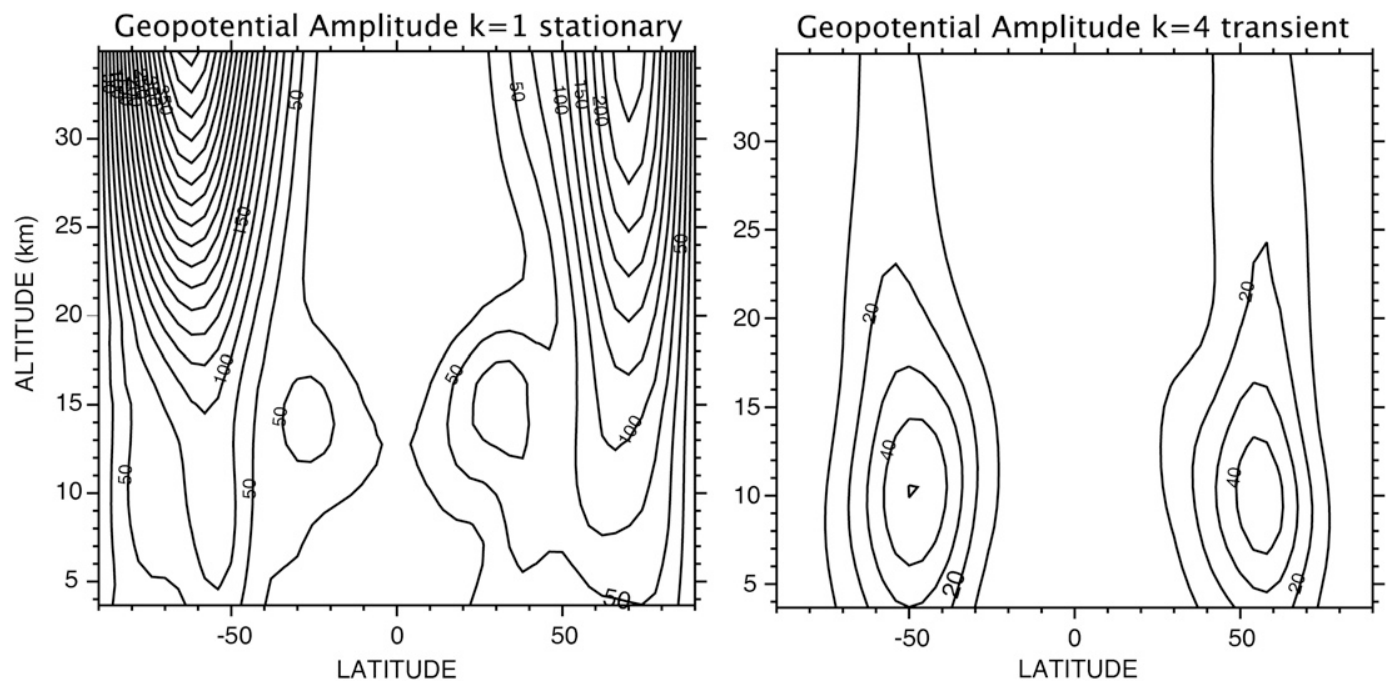

FIG. 6. Geopotential height wave amplitude from the REF1 simulation (1950-2003) for (left) the stationary $k=1$ component (contour interval $25 \mathrm{~m}$ ) and (right) the transient $k=4$ component (contour interval $10 \mathrm{~m}$ ) of the resolved wave field. 

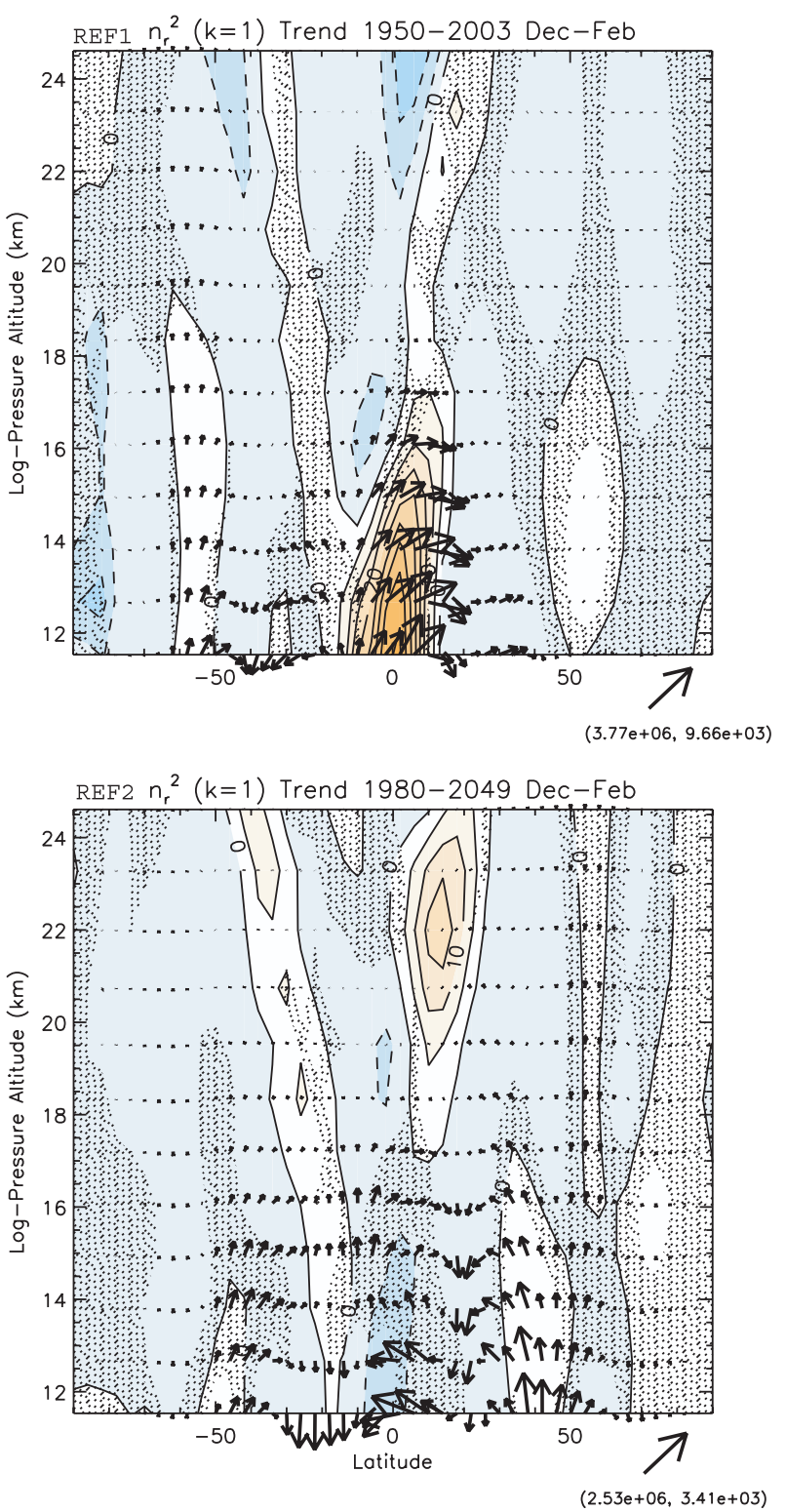

FIG. 7. Trend in quasigeostrophic index of refraction squared for simulations (top) REF1 and (bottom) REF2 in Northern Hemisphere winter (DJF), for the $k=1$ wave component. The trend in vector EP flux $\left(\mathrm{kg} \mathrm{m}^{-2}\right.$ decade $\left.^{-1}\right)$ is superimposed. Stippled regions are not significant at the $95 \%$ level.

reaches the lower stratosphere in the tropics and subtropics is a very small fraction of the total wave activity generated in the troposphere (cf. GR08, their Fig. 5), it is possible that there are trends in wave forcing that are difficult to detect by examining tropospheric EP flux. Here we look instead at changes in latent heat release by tropical convection, since these are presumed to be the chief mechanism of wave excitation in the tropics (see, e.g., Gill 1980; Garcia and Salby 1987, among many others).
Figure 8 shows percentage differences in convective heating between the first and last decades of simulations REF1 and REF2 for the RMS sum of wave components $k=1-3$. The time-mean convective heating pattern in both cases (not shown) maximizes in the middle troposphere, around 5-6 km of altitude, and the heating rates become small above 11-12 km, so any extension of latent heating into the upper tropical troposphere due to more vigorous convection will produce large percentage changes in that region. Nonetheless, we show percentage changes only where the local heating rates are at least $10 \%$ of the maximum heating rates in midtroposphere to avoid the appearance of very large changes at altitudes where the heating rates are insignificantly small. In the REF1 simulation, Fig. 8 indicates that changes in convective heating are small almost everywhere, except for a narrow region close to the equator, between $5^{\circ} \mathrm{S}$ and $10^{\circ} \mathrm{N}$, and below $11 \mathrm{~km}$. In simulation REF2, on the other hand, substantial percentage differences in convective heating extend throughout the tropics, between about $15^{\circ} \mathrm{S}$ and $30^{\circ} \mathrm{N}$, and they reach higher altitudes, with $10 \%$ changes seen near the equator up to $14 \mathrm{~km}$. This suggests that, in simulation REF2, increases in convective heating may be responsible for the trend in EP flux in the lower stratosphere via increased wave excitation. In fact, examination of trends in wave amplitude for stationary, planetary-scale waves shows amplitude increases of $10 \%-30 \%$ in the tropical lower stratosphere over the period (1980-2050) covered by simulation REF2 (not shown). These results are consistent with the findings of Deckert and Dameris (2008), who used two simulations with different SSTs to show that higher tropical SSTs in the summer hemisphere intensify the tropical upwelling due to deepconvective generation of quasi-stationary waves that dissipate in the tropical lower stratosphere. Oman et al. (2009) also analyzed the effect of SSTs on tropical upwelling in GEOS GCM simulations and discussed the rate in tropical mass flux over time in the models analyzed in Butchart et al. (2006). The largest rates are obtained in those models that have higher than average SST rate increases (mid-to-late twenty-first century) while the lowest three rates are those from model runs where the SST were fixed.

There remains the question why, in our REF1 simulation, trends in wave driving appear to be the result of wave-enhanced transmissivity into the subtropical lower stratosphere, while in REF2 stronger wave driving seems to follow from enhanced wave excitation via convective heating. We do not know the answer to this question, but we can at least ask whether differences in the SSTs specified in simulations REF1 and REF2 might play a role. REF1 uses SSTs derived from the Hadley 


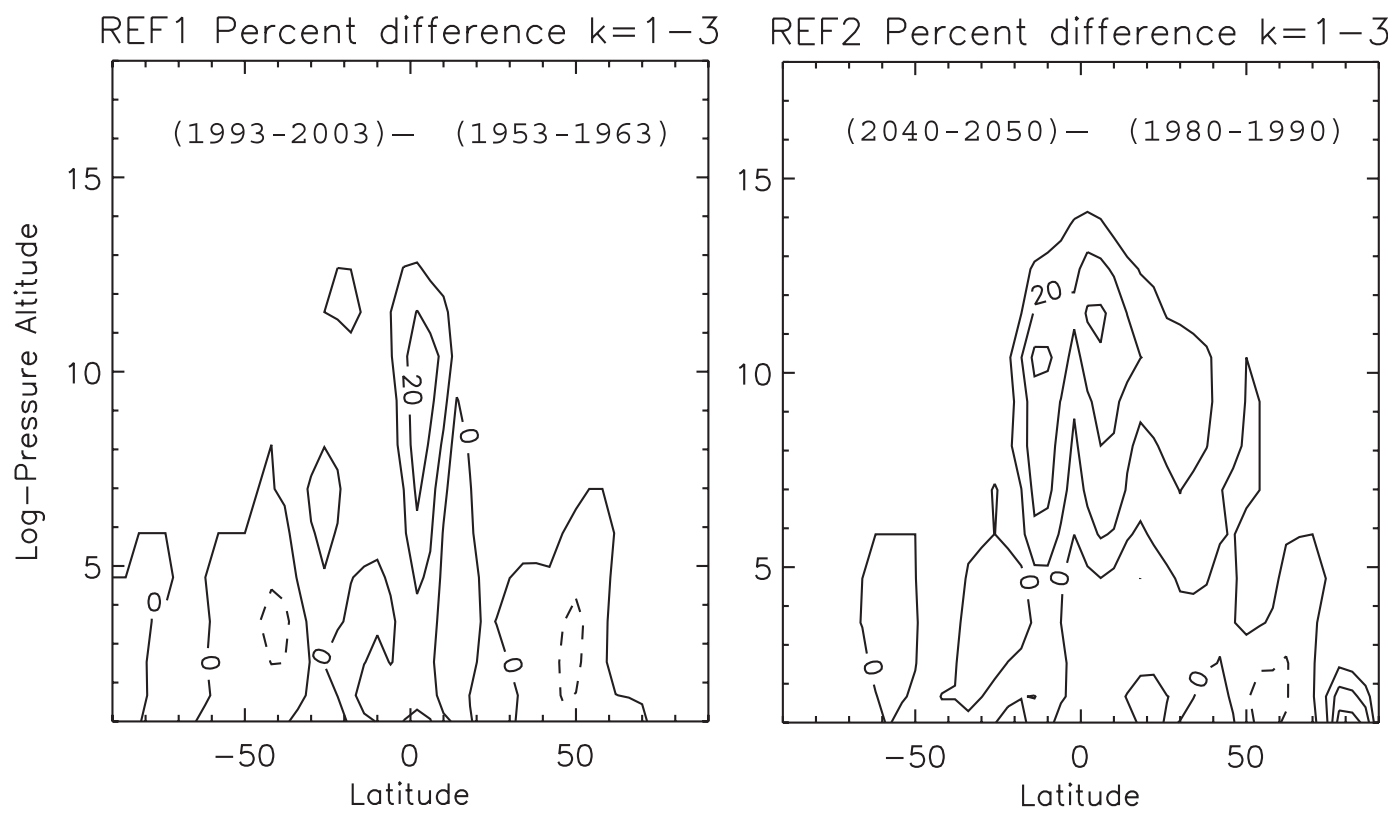

FIG. 8. Percentage changes in the rate of latent heat release by tropical convection for simulations (left) REF1and (right) REF2 of the planetary wave components $k=1-3$. For REF1, this is the difference between the time means for the periods 1953-63 and 1993-2003; for REF2, it is the difference between he time means for the periods 1980-90 and $2040-50$.

Centre dataset, while the SSTs in REF2 are taken from coupled simulations of the twenty-first century made with the CAM3 model, upon which WACCM is based (see Garcia et al. 2007 for details). Because SSTs have a strong influence on the development of deep convection in the tropics, one might suspect that there is something intrinsically different in the evolution of the SSTs in the two simulations that influences the trend (or lack of it) in convective heating and/or the structure of the tropical temperature field, which leads to changes in the zonal wind and hence the index of refraction. We address this question by comparing the behavior of both the index of refraction and the rate of convective heating in REF1 and REF2 over the 20-yr period 1984-2003, which is common to both simulations. Figure 9 shows the trends in index of refraction and suggests that, during 19842003, changes in index of refraction near the equator were such as to facilitate wave transmission in both simulations. We note that the results for REF1 are not statistically significant at the $95 \%$ level, but nevertheless the change in $n_{r}^{2}$ is in the same sense as in REF2. On the other hand, when changes in convective heating over 1984-2003 were compared, they were found to be small for both simulations (not shown). Taken together, these results suggest that both the index of refraction and the convective excitation mechanism operate in simulation REF2, with a transition from enhanced transmissivity to stronger wave excitation occurring in the twenty-first century. (We calculated changes in convective heating in simulation REF2 for the period 2000-50, with results similar to those shown in Fig. 8.)

We note finally that there are also increases in wave driving by transient waves in Figs. 1 and 2 that are not explained by either of the mechanisms proposed above. As suggested by Eichelberger and Hartmann (2005), these changes may be due to increased baroclinicity of the midlatitude jets, which become stronger as the troposphere warms (and the stratosphere cools) under the increasing load of GHGs. We have not pursued this issue here as the EP flux divergence associated with transient, synoptic waves is centered mainly at midlatitudes and contributes relatively little to tropical upwelling in the lower stratosphere, which is the focus of the present investigation.

\section{Summary and conclusions}

The role of different waves in driving increases in tropical upwelling in the lower stratosphere under increasing concentrations of greenhouse gases has been investigated in two simulations carried out with WACCM: a retrospective simulation of the second half of the twentieth century (1950-2003) and a prognostic simulation that extends into the twenty-first century (19802050) and follows scenario A1B of the IPCC. Garcia and Randel (2008) showed previously that the acceleration 

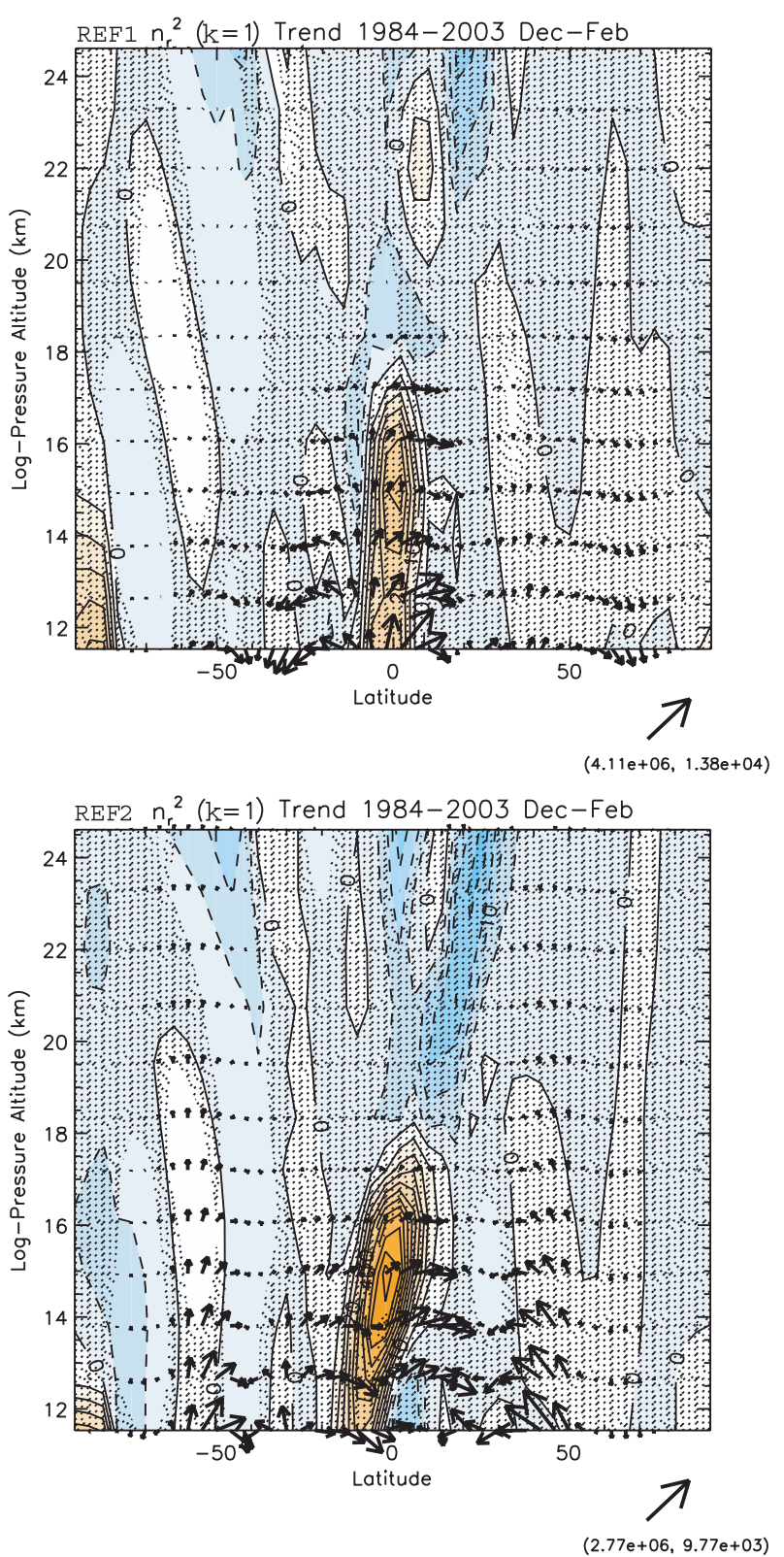

FIG. 9. As in Fig. 7 but for the period 1984-2003, which is common to both simulations REF1 and REF2.

of the $\mathrm{BD}$ circulation in the tropical lower stratosphere in WACCM is due in large part to changes in wave driving by resolved waves, which they suggested follow from changes in the zonal-mean zonal wind and temperature distributions forced by greenhouse gases. Here the trends in the vertical upwelling, EP flux, and EP flux divergence have been analyzed by decomposition of the resolved wave fields into stationary and transient zonal wavenumber components to isolate the waves that contribute most to the increase in tropical upwelling. We have also presented some new evidence that sheds light on the mechanisms responsible for the calculated trends in wave forcing.

Stationary waves, mainly of planetary scale $(k=1-3)$, account for most of the trend in the tropical-mean vertical velocity $\left\langle\bar{w}^{*}\right\rangle$ in the lower stratosphere calculated with WACCM. These waves originate in tropical latitudes, and their structure indicates that they are equatorially trapped Rossby waves. Transient waves are responsible for most of the trends in wave forcing in the subtropics and middle latitudes; they are mainly synoptic waves trapped in the troposphere and lower stratosphere. Their contribution to the mean tropical upwelling is, however, much smaller than that from stationary planetary waves. This happens because the tropical mean vertical velocity is driven by the wave forcing at the edge of the tropical region (defined here as $\pm 22^{\circ}$ ), while the synoptic-scale transients contribute mainly to the wave dissipation at extratropical latitudes.

We have made use of index of refraction arguments to show that, in simulation REF1 (1950-2003), changes in the tropical zonal-mean zonal wind distribution lead to positive trends in the index of refraction in the deep tropics, such that propagation from the troposphere to the lower stratosphere becomes increasingly favorable there. On the other hand, in simulation REF2 (19802050) we do not find significant changes in the index of refraction. Instead, increasing wave activity in the tropical lower stratosphere appears to be associated with an upward expansion of the region of latent heat release by tropical convection, with local increases reaching the tropical upper troposphere, and a concomitant enhancement of planetary wave amplitudes in the upper troposphere and lower stratosphere.

The fact that different mechanisms are found to operate in the two simulations could be related to the specification of SSTs, which are taken form the Hadley Centre observational dataset in REF1, but in REF2 are prescribed from coupled runs of NCAR's CAM3, upon which WACCM is based. However, a comparison of changes in refractive index and convective heating over the common period 1983-2003 shows similar behavior in both REF1 and REF2 (the index of refraction becomes more favorable to wave propagation, while changes in convective heating are minor). This suggests that, in REF2, there is a transition from a period, in the late twentieth century, when changes in index of refraction are dominant, to a period, in the twenty-first century, when enhanced convective heating is principally responsible for changes in wave driving. In the case of latent heat release, it appears then that the higher SSTs in the future climate have a stronger influence on the tropical upwelling through the generation of stationary planetary waves, in agreement with the work of Deckert and Dameris (2008) and Oman et al. (2009). 
We close by cautioning that the mechanisms found here responsible for the trends in tropical upwelling might be model dependent. Although most models appear to be consistent in predicting that enhanced wave driving by planetary-scale waves is responsible for the acceleration of tropical upwelling, the mechanisms that bring this about could differ among models. New analyses with other models will need to be carried out to explore the generality of the present results.

Acknowledgments. N. Calvo was supported by the Spanish Ministry of Education and Science, and the Fulbright Commission in Spain. The WACCM simulations were carried out at the National Center for Atmospheric Research (NCAR) in Boulder, Colorado; at the NASA Advanced Supercomputing Division (NAS) in Ames, California; and at the Barcelona Supercomputing Center (BSC) in Barcelona, Spain. The use of these computational facilities is gratefully acknowledged. We also thank two anonymous referees for their insightful reviews.

\section{REFERENCES}

Butchart, N., and A. A. Scaife, 2001: Removal of chlorofluorocarbons by increased mass exchange between the stratosphere and troposphere in a changing climate. Nature, 410, 799-802.

— , and Coauthors, 2006: Simulations of anthropogenic change in the strength of the Brewer-Dobson circulation. Climate Dyn., 27, 727-741, doi:10.1007/s00382-006-0162-4.

Deckert, R., and M. Dameris, 2008: Higher tropical SSTs strengthen the tropical upwelling via deep convection. Geophys. Res. Lett., 35, L10813, doi:10.1029/2008GL033719.

Edmon, H. J., B. J. Hoskins, and M. E. McIntyre, 1980: EliassenPalm flux cross sections for the troposphere. J. Atmos. Sci., 37, 2600-2616.

Eichelberger, S. J., and D. L. Hartmann, 2005: Changes in the strength of the Brewer Dobson circulation in a simple AGCM. Geophys. Res. Lett., 32, L15807, doi:10.1029/2005GL.22924.

Fomichev, V. I., A. I. Jonsson, J. de Grandpre, S. R. Beagley, C. McLandress, K. Semeniuk, and T. G. Shepherd, 2007: Response of the middle atmosphere to $\mathrm{CO}_{2}$ doubling: Results from the Canadian Middle Atmosphere Model. J. Climate, 20, 1121-1144.

Garcia, R. R., and M. L. Salby, 1987: Transient response to localized episodic heating in the tropics. Part II: Far-field behavior. J. Atmos. Sci., 44, 499-530.
—_ and W. J. Randel, 2008: Acceleration of the Brewer-Dobson circulation due to increases in greenhouse gases. J. Atmos. Sci., 65, 2731-2739.

_ - D. R. Marsh, D. E. Kinninson, B. A. Boville, and F. Sassi, 2007: Simulations of secular trends in the middle atmosphere, 1950-2003. J. Geophys. Res., 112, D09301, doi:10.1029/ 2006JD007485.

Gill, A. E., 1980: Some simple solutions for heat induced tropical circulation. Quart. J. Roy. Meteor. Soc., 106, 447-462.

Hall, T. M., and R. A. Plumb, 1994: Age as a diagnostic of stratospheric transport. J. Geophys. Res., 99, 1059-1070.

Haynes, P. H., M. E. McIntyre, T. G. Shepherd, C. J. Marks, and K. P. Shine, 1991: On the "downward control" of extratropical diabatic circulations by eddy-induced mean zonal forces. J. Atmos. Sci., 48, 651-678.

Holton, J. R., 1992: An Introduction to Dynamic Meteorology. Academic Press, 511 pp.

Houghton, J. T., Y. Ding, D. J. Griggs, M. Noguer, P. J. van der Linden, X. Dai, K. Maskell, and C. A. Johnson, Eds., 2001: Climate Change 2001: The Scientific Basis. Cambridge University Press, $881 \mathrm{pp}$.

Li, F., J. Austin, and J. Wilson, 2008: The strength of the BrewerDobson circulation in a changing climate: Coupled chemistryclimate model simulations. J. Climate, 21, 40-57.

Matsuno, T., 1970: Vertical propagation of stationary planetary waves in the Northern Hemisphere. J. Atmos. Sci., 27, 871-883.

McLandress, C., and T. Shepherd, 2009: Simulated anthropogenic changes in the Brewer-Dobson circulation, including its extension to high latitudes. J. Climate, 22, 1516-1540.

Olsen, M. A., M. R. Schoeberl, and J. E. Nielsen, 2007: Response of stratospheric circulation and stratosphere-troposphere exchange to changing sea surface temperatures. J. Geophys. Res., 112, D16104, doi:10.1029/2006JD008012.

Oman, L., D. W. Waugh, S. Pawson, R. S. Stolarski, and P. A. Newman, 2009: On the influence of anthropogenic forcings on changes in the stratospheric mean age. J. Geophys. Res., 114, D03105, doi:10.1029/2008JD010378.

Rind, D., J. Lerner, and C. McLinden, 2001: Changes in tracer distributions in the doubled $\mathrm{CO} 2$ climate. J. Geophys. Res., 106 (D22), 28 061-28 080.

Shindell, D. T., G. A. Schmidt, R. L. Miller, and D. Rind, 2001: Northern Hemisphere winter climate response to greenhouse gas, volcanic, ozone and solar forcing. J. Geophys. Res., 106, 7193-7210.

Sigmond, M., P. C. Siegmund, E. Manzini, and H. Kelder, 2004: A simulation of the separate climate effects of middleatmospheric and tropospheric $\mathrm{CO} 2$ doubling. J. Climate, 17, 2352-2367.

WMO, 2003: Scientific assessment of ozone depletion: 2002. Rep. 47, Global Research and Monitoring Project, Geneva, 498 pp. 